Article

\title{
Enhanced Activity of Supported Ni Catalysts Promoted by Pt for Rapid Reduction of Aromatic Nitro Compounds
}

\author{
Huishan Shang ${ }^{1,2}$, Kecheng Pan ${ }^{1}$, Lu Zhang ${ }^{1}$, Bing Zhang ${ }^{2, *}$ and Xu Xiang ${ }^{1, *}$ \\ 1 State Key Laboratory of Chemical Resource Engineering, Beijing University of Chemical Technology, \\ Beijing 100029, China; huishan6880220@163.com (H.S.); xiangxubit@sohu.com (K.P.); \\ zhanglu@mail.buct.edu.cn (L.Z.) \\ 2 School of Chemical Engineering, Zhengzhou University, Zhengzhou 450001, China \\ * Correspondence: zhangb@zzu.edu.cn (B.Z.); xiangxu@mail.buct.edu.cn (X.X.); \\ Tel.: +86-371-6778-1724 (B.Z.); +86-10-6443-2931 (X.X.)
}

Academic Editors: Hermenegildo García and Sergio Navalón Received: 22 April 2016; Accepted: 13 May 2016; Published: 4 June 2016

\begin{abstract}
To improve the activities of non-noble metal catalysts is highly desirable and valuable to the reduced use of noble metal resources. In this work, the supported nickel (Ni) and nickel-platinum $(\mathrm{NiPt})$ nanocatalysts were derived from a layered double hydroxide/carbon composite precursor. The catalysts were characterized and the role of Pt was analysed using X-ray diffraction (XRD), high-resolution transmission electron microscopy (HRTEM), energy dispersive $X$-ray spectroscopy (EDS) mapping, and $\mathrm{X}$-ray photoelectron spectroscopy (XPS) techniques. The $\mathrm{Ni}^{2+}$ was reduced to metallic $\mathrm{Ni}^{0}$ via a self-reduction way utilizing the carbon as a reducing agent. The average sizes of the Ni particles in the NiPt catalysts were smaller than that in the supported Ni catalyst. The electronic structure of Ni was affected by the incorporation of Pt. The optimal NiPt catalysts exhibited remarkably improved activity toward the reduction of nitrophenol, which has an apparent rate constant $\left(K_{\mathrm{a}}\right)$ of $18.82 \times 10^{-3} \mathrm{~s}^{-1}, 6.2$ times larger than that of Ni catalyst and also larger than most of the reported values of noble-metal and bimetallic catalysts. The enhanced activity could be ascribed to the modification to the electronic structure of $\mathrm{Ni}$ by Pt and the effect of exposed crystal planes.
\end{abstract}

Keywords: supported catalysts; heterogeneous catalysis; nickel; platinum; reduction

\section{Introduction}

Aromatic nitro compounds are widely generated as byproducts in various industries, including in the production of pigments, pesticides and medicines [1]. 4-nitrophenol (4-NP) is among the most common aromatic nitro compounds, and is harmful to the environment [2]. 4-aminophenol (4-AP), the reduction product of 4-NP, is an important intermediate for the manufacture of dyes, agrochemicals, and pharmaceuticals [3-5].

Various methods to synthesize 4-AP have been reported, such as multi-step iron-acid reduction of 4-NP, catalytic reduction of nitrobenzene, and electrochemical synthesis [6-8]. Among these methods, catalytic reduction is an alternative green process for 4-AP production because it does not generate a large amount of un-reusable $\mathrm{Fe}-\mathrm{FeO}$ sludges and acid/alkali effluents [9]. It is well known that diverse noble metal such as palladium, platinum, and gold catalysts have been widely used in the catalytic reactions due to their high catalytic activities [10-13]. However, the high cost and scarcity in nature limit their practical applications. Therefore, non-noble metal catalysts have been paid more attention because of their abundance and reduced cost [14]. As we know, the reduction rates of 4-NP to 4-AP over non-noble metal catalysts are far slower than noble metal ones [15]. Therefore, it is desirable to improve the catalytic activities of the supported non-noble metal catalysts. 
Among non-noble metals, nickel nanoparticles (Ni NPs) have drawn much attention because of their easy availability, relatively high catalytic activity, and magnetic separation feature $[16,17]$. Moreover, the unique physical and chemical properties can be introduced by adding a small amount of second elements such as Pd, Pt, Ir, or Ru to Ni catalysts. These elements are dispersed on the surface of $\mathrm{Ni}$ to form bimetallic catalysts and the interactions at the metal-metal interface lead to the improved performance of Ni catalysts [18-21]. Thus, a promising endeavor is to explore a combination of noble metal, e.g., Pt and Ni NPs to enhance the catalytic activity. In addition, the Ni-based catalysts can be easily separated from the reaction medium by application of an external magnetic field.

In the previous work, we prepared supported $\mathrm{Ni}$ catalysts via self-reduction of hybrid NiAl-layered double hydroxide/carbon (NiAl-LDH/C) composites [22]. The composites were assembled via crystallization of LDH in combination with simultaneous carbonization of glucose under hydrothermal conditions. The resulting carbon acted as a reducing agent to convert nickel oxide to metallic nickel upon calcination. The as-synthesized Ni nanoparticles had small crystallite sizes and high dispersions in the support owing to the confined effects of LDH and carbon. Inspired by this finding, we extended this method to prepare Pt-modified Ni catalysts. The glucose-derived carbon in the composites led to in situ reduction of chloroplatinic acid anions upon hydrothermal carbonization and thus introduced $\mathrm{Pt}$ to the Ni catalysts. The catalytic activities of the resultant Pt-modified Ni catalysts for liquid-phase reduction of 4-NP to 4-AP were investigated under mild reaction conditions. The optimal NiPt catalysts exhibited larger apparent rate constant $\left(K_{\mathrm{a}}\right)$ than most of the reported values of noble-metal and bimetallic catalysts.

\section{Results and Discussions}

\subsection{Characterization of Materials}

The XRD patterns of LDH, hybrid LDH/C and Pt@LDH/C composites were shown in Figure 1a. The pattern of LDH sample exhibited the characteristic (003), (006), (009), (110), and (113) reflections, corresponding to layered hydrotalcite-like compounds [23]. The intensive reflections revealed the highly crystalline nature of the product. In contrast, the patterns of LDH/C and Pt@LDH/C composites presented broadened reflections at the same $2 \theta$ positions as those of $\mathrm{LDH}$. It was noted that no graphite or other forms of carbon phases were detected, suggesting that carbon products mostly existed in amorphous form. The broader and weaker reflections for LDH/C and Pt@LDH/C were caused by both the dilution effect of the resultant carbon component in the composites and the reduced crystalline feature of LDH phase. No reflections associated with metal Pt or other Pt species were observed in Pt@LDH/C. This finding could be ascribed to the high dispersion of the Pt nanoparticles of small sizes and/or the very low loading [24]. It was believed that the aromatization and carbonization of glucose yielded amorphous carbon under the present hydrothermal treatment [25], and the resultant carbon was assembled with LDH crystallites during the crystallization of LDH, thereby leading to the formation of hybrid composites.

The effects of calcination temperatures on the phase structure were also studied. Figure $1 \mathrm{~b}$ showed XRD patterns of Pt@LDH/C precursor calcined at $500{ }^{\circ} \mathrm{C}, 600^{\circ} \mathrm{C}$, and $700{ }^{\circ} \mathrm{C}$ in a flowing $\mathrm{N}_{2}$ atmosphere. It was known that the layered structure of $\mathrm{LDH}$ collapses and is converted into mixed-oxide phases when heating above $450{ }^{\circ} \mathrm{C}$ [26]. For NiPt-0.6\% (500) and NiPt- $0.6 \%$ (600) samples, the XRD patterns exhibited the co-existence of $\mathrm{Ni}$ and $\mathrm{NiO}$ phases. Furthermore, the relative intensity from the reflections of $\mathrm{NiO}$ decreased with increasing calcination temperature. After elevating the temperature to $700{ }^{\circ} \mathrm{C}$, only the contributions from metallic $\mathrm{Ni}$ were observed, which can be indexed to the face-centered cubic (fcc) Ni phase (JCPDS No. 87-0712). The three peaks centered at $2 \theta=44.4^{\circ}$, $51.7^{\circ}$ and $76.5^{\circ}$ corresponded to the characteristic (111), (200) and (220) planes of Ni phase. The results indicated that the complete phase transformation from $\mathrm{NiO}$ to $\mathrm{Ni}$ occurred at this temperature. 

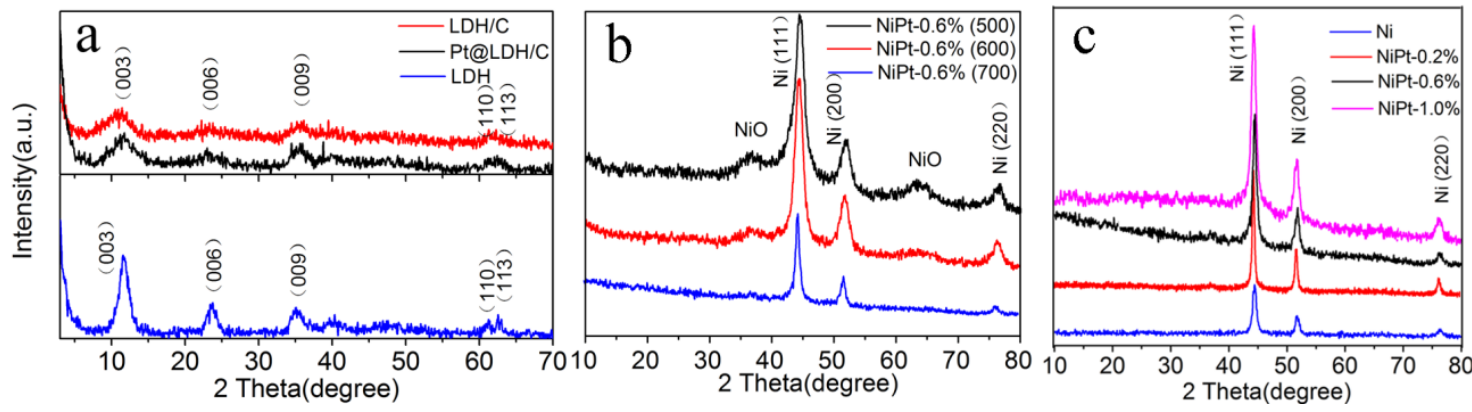

Figure 1. X-ray diffraction (XRD) patterns of (a) layered double hydroxide (LDH), LDH/carbon (C), and Pt@LDH/C; (b) NiPt catalysts obtained at different calcination temperatures; and (c) the Ni and NiPt catalysts with different Pt loadings.

The LDH-derived metal oxides could be reduced into metal via self-reduction by carbon in the $\mathrm{LDH} / \mathrm{C}$ composite, leading to the tranformation of $\mathrm{Ni}^{2+}$ to $\mathrm{Ni}^{0}$. The main reactions can be expressed as follows:

$$
\begin{gathered}
\mathrm{NiO}+\mathrm{C}(\mathrm{s}) \rightarrow \mathrm{Ni}+\mathrm{CO}(\mathrm{g}) \\
\mathrm{NiO}+\mathrm{CO}(\mathrm{g}) \rightarrow \mathrm{Ni}+\mathrm{CO}_{2}(\mathrm{~g})
\end{gathered}
$$

During heating, LDH was transformed into mixed oxides (crystalline $\mathrm{NiO}$ and amorphous alumina). After reduction, the residual carbon acted not only as the support but also as the dispersing matrix, which prevented Ni particles from agglomeration. Figure 1c showed the XRD patterns of $\mathrm{NiPt}$ catalysts with different Pt loadings. These XRD patterns of the $\mathrm{Ni}$ and NiPt samples were hardly distinguishable, which could indicate that the Pt species were highly dispersed in the NiPt catalysts [27].

TEM observations were carried out to investigate the morphologies and microstructures of NiPt catalysts with different Pt loadings (Figure 2). TEM-derived histograms of the Ni particle size distributions were presented. The TEM images indicated that the Ni nanoparticles were well dispersed on the support and the size slightly decreased from 12.1 to $11.0 \mathrm{~nm}$ when the nominal Pt content was increased to $0.6 \%$ compared to the pristine Ni. When the Pt content was increased to $1.0 \%$, the Ni nanoparticles had smaller size $(\sim 9 \mathrm{~nm})$ and narrower size distributions (Table 1$)$. The Ni loading reached as high as $36 \%-39 \%$ whereas no obvious aggregates were observed, suggestive of excellent metal dispersion. The Pt particles could not be found in the TEM images owing to the low loading. The Pt loading measured was lower than the nominal value, possibly due to the metal leaching during the hydrothermal reactions (Table 1). One can find that these catalysts had similar specific surface areas, which indicated that the surface area could not be the dominant factor to adjust the catalytic properties [28].

Table 1. Metal loadings, sizes and specific surface areas of the supported catalysts.

\begin{tabular}{ccccc}
\hline Catalyst & Pt wt $_{\mathbf{~}} \mathbf{1}$ & Ni wt $\%$ & D $(\mathbf{n m})^{\mathbf{2}}$ & Specific Surface Area $\left(\mathbf{m}^{\mathbf{2}} \mathbf{g}^{-\mathbf{1}} \mathbf{~}^{\mathbf{3}}\right.$ \\
\hline $\mathrm{Ni}$ & 0 & 35.85 & 12.1 & 244.6 \\
$\mathrm{NiPt}-0.2 \%$ & 0.167 & 38.75 & 12.1 & 271.8 \\
$\mathrm{NiPt}-0.6 \%$ & 0.347 & 36.98 & 11.0 & 266.0 \\
$\mathrm{NiPt}-1.0 \%$ & 0.537 & 39.55 & 9.0 & 267.4 \\
\hline
\end{tabular}

${ }^{1} \mathrm{Pt}$ content measured by inductively coupled plasma-atomic emission spectroscopy (ICP-AES); ${ }^{2}$ The mean size of Ni nanoparticles (NPs) based on TEM analysis; ${ }^{3}$ Specific surface area calculated by a Brunauer-Emmett-Teller (BET) method. 

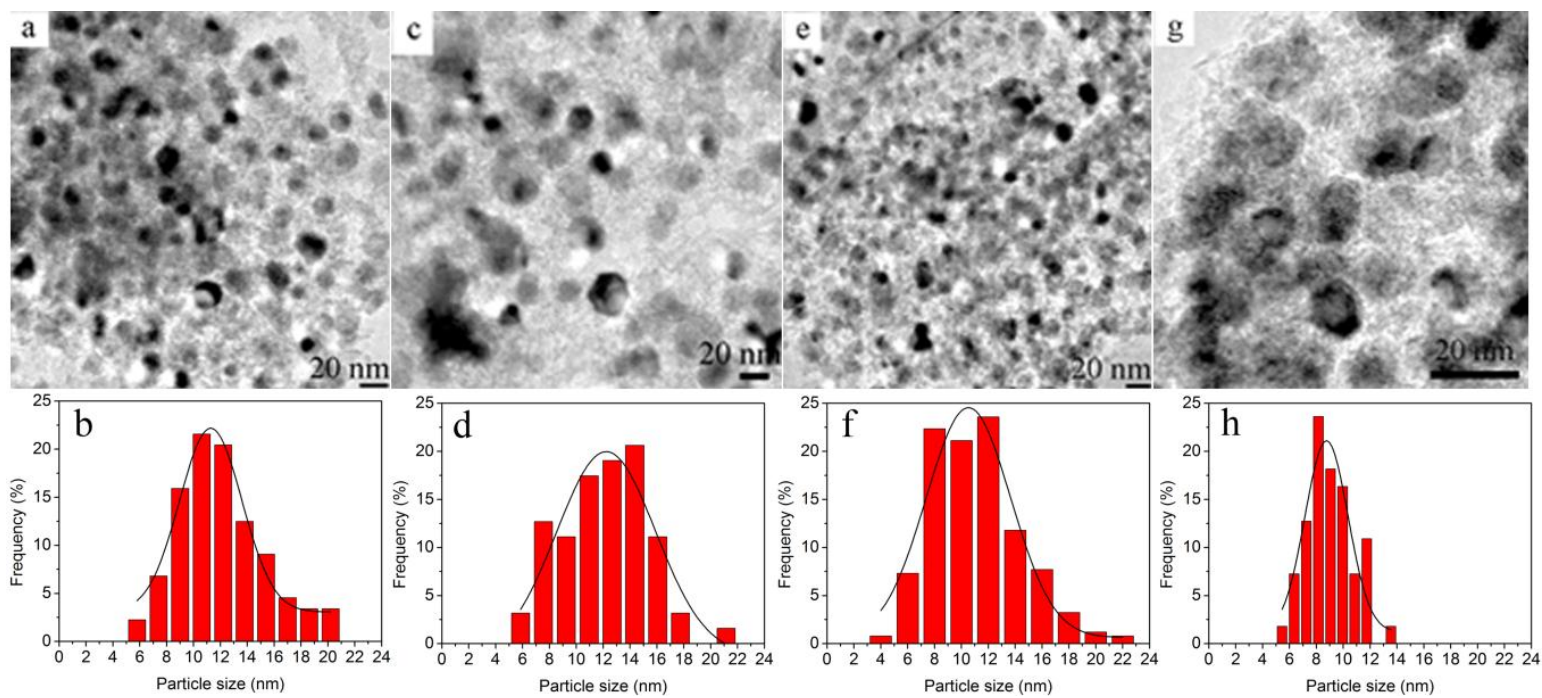

Figure 2. Transmission electron microscopy (TEM) images and size distributions of the supported Ni and NiPt catalysts with different Pt loadings (a) and (b) Ni; (c) and (d) NiPt- $0.2 \%$; (e) and (f) NiPt- $0.6 \%$; (g) and (h) NiPt-1.0\%.

To further reveal the microstructures of the $\mathrm{Ni}$ and Pt NPs, high-resolution transmission electron microscopy (HRTEM) observations were conducted. As shown in Figure 3a, the lattice spacing of the supported Ni NPs was measured to be $0.203 \mathrm{~nm}$, consistent with the d-value of plane (111) of cubic phase Ni. Regarding NiPt- $0.2 \%$ and NiPt- $1.0 \%$ catalysts, the Ni NPs had the same d-spacing of 0.203 $\mathrm{nm}$ (Figure 3b,d), and the Pt NPs exhibited a d-spacing of $0.230 \mathrm{~nm}$, corresponding to plane (111) of Pt. The adjacent interface could be observed between plane $\mathrm{Ni}$ (111) and $\mathrm{Pt}$ (111). As to NiPt-0.6\% catalysts, the d-spacing of $0.170 \mathrm{~nm}$ for Ni NPs and $0.193 \mathrm{~nm}$ for Pt NPs were observed, which corresponded to $\mathrm{Ni}(200)$ and $\mathrm{Pt}$ (200), respectively (Figure 3c). It was interesting that the interface formed between $\mathrm{Ni}$ (111) and Pt (111) or Ni (200) and Pt (200). Such interface of different planes of Ni and Pt NPs could affect the catalytic properties. It is known that the catalytic reduction usually depends on the sizes, shapes, and/or exposed planes of the active metal NPs [23,29]. The differences in exposed planes and interfaces of NiPt catalysts could lead to distinct activities towards the reduction reaction. Energy dispersive $\mathrm{X}$-ray spectroscopy (EDS) mapping analyses of $\mathrm{NiPt}-0.6 \%$ exhibited $\mathrm{C}, \mathrm{O}, \mathrm{Al}, \mathrm{Ni}$, and $\mathrm{Pt}$ elements (Figure $3 \mathrm{e}$ ). It was seen that $\mathrm{C}, \mathrm{O}$ and $\mathrm{Al}$ were homogeneously distributed in the whole matrix. The Ni components were highly dispersed on the matrix and as well the small amount of Pt.

X-ray photoelectron spectroscopy (XPS) measurements were used to analyze the chemical states of the metal species in the catalysts. The XPS spectra of Pt and Ni core levels were shown in Figure 4. The Pt4f spectra could be deconvoluted into two peaks due to the spin-orbit splitting. One was at 70.9-71.4 eV, and the other was at 74.2-75.0 eV, which could be assigned to metallic $\mathrm{Pt}^{0}$ species $[30,31]$. As to NiPt- $1.0 \%$ sample, the Pt4f peaks showed a $0.5-0.8 \mathrm{eV}$ shift towards a higher binding energy compared to the other two NiPt catalysts (Table 2). This was an indication that the electronic structures of Pt were affected by the surrounding Ni NPs owing to the strong interactions between them [32]. The Ni2p spectra were deconvoluted into three contributions at $\sim 853.3, \sim 856.8$, and $\sim 862.5 \mathrm{eV}$ in the $\mathrm{Ni} 2 \mathrm{p}_{3 / 2}$ region, which were assigned to the metallic $\mathrm{Ni}^{0}$, the $\mathrm{Ni}^{2+}$ species in $\mathrm{NiO}$ and the satellite, respectively [33]. The existence of $\mathrm{Ni}^{2+}$ species could be due to the easy oxidation of metallic $\mathrm{Ni}$, which inevitably contact with the air during the sample preparation and settlement [22]. Compared to the $\mathrm{Ni}$ catalysts, the binding energy of $\mathrm{Ni}^{0}$ and $\mathrm{Ni}^{2+}\left(\mathrm{Ni} 2 \mathrm{p}_{3 / 2}\right)$ in the $\mathrm{NiPt}-0.2 \%$ had a little shift of $0.1-0.2 \mathrm{eV}$ towards a lower value. The binding energy shifted $\sim 0.4 \mathrm{eV}$ with the increasing Pt content in the NiPt- $0.6 \%$ and NiPt-1.0\% samples (Table 2). The binding energy of metallic Ni shifted to a lower value after a small amount of $\mathrm{Pt}$ was incorporated. It is a hint that the electronic structures of $\mathrm{Ni}$ were affected by Pt, suggesting the strong interactions between the two metal components. The binding 
energy at $68.9 \mathrm{eV}$ could be the contribution from Ni3p [34,35]. The Ni3p peak overlapped with the $\mathrm{Pt}_{4} \mathrm{f}_{7 / 2}$ peak, which provided further evidence for the existence of interactions between $\mathrm{Ni}$ and $\mathrm{Pt}$. The binding energy at $74.8 \pm 0.1 \mathrm{eV}$ was assigned to $\mathrm{Al} 2 \mathrm{p}$ core level, which came from the $\mathrm{Al}_{2} \mathrm{O}_{3}$ matrix in the catalysts [36]. XPS characterization verified that the interactions between $\mathrm{Ni}$ and $\mathrm{Pt}$ were enhanced with the increasing content of $\mathrm{Pt}$.

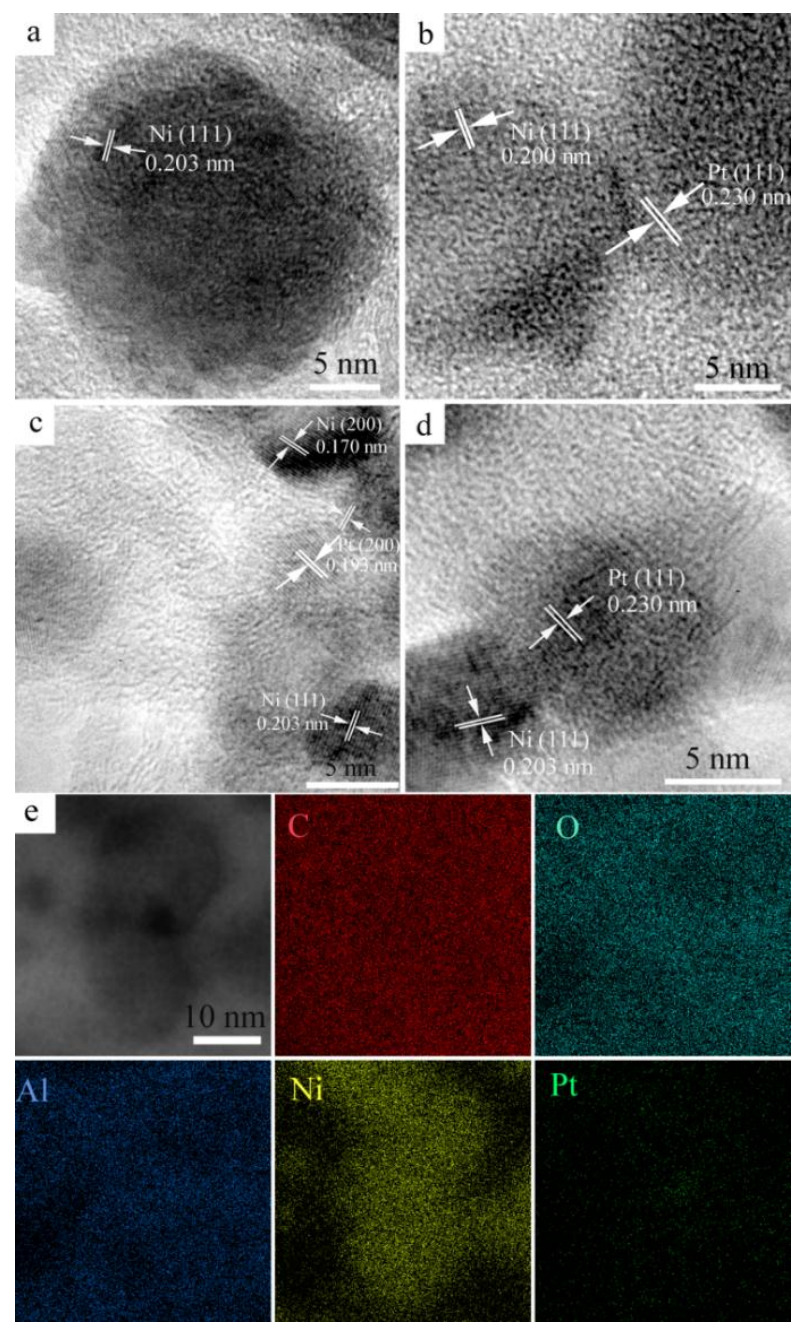

Figure 3. High-resolution transmission electron microscopy (HRTEM) images of the supported catalysts: (a) Ni; (b) NiPt-0.2\%; (c) NiPt-0.6\%; (d) NiPt-1.0\%; (e) Energy dispersive X-ray spectroscopy (EDS) mapping of the catalyst NiPt- $0.6 \%$.

Table 2. XPS binding energy of the Ni, Pt and Al core levels in the supported catalysts.

\begin{tabular}{|c|c|c|c|c|c|c|c|c|c|c|}
\hline \multirow{2}{*}{ Catalysts } & \multicolumn{3}{|c|}{$2 p_{3 / 2}(e V)$} & \multicolumn{3}{|c|}{$2 p_{1 / 2}(e V)$} & $4 f_{7 / 2}(e V)$ & $4 f_{5 / 2}(e V)$ & \multirow{2}{*}{ Ni3p } & \multirow{2}{*}{ Al2p } \\
\hline & $\mathrm{Ni}^{0}$ & $\mathrm{Ni}^{2+}$ & $\mathrm{Ni}^{\text {Sat. }}$ & $\mathrm{Ni}^{0}$ & $\mathrm{Ni}^{2+}$ & $\mathrm{Ni}^{\text {Sat. }}$ & \multicolumn{2}{|c|}{$\mathbf{P t}^{0}$} & & \\
\hline $\mathrm{Ni}$ & 853.3 & 856.8 & 862.5 & 870.9 & 874.4 & 880.5 & - & - & - & 74.8 \\
\hline $\mathrm{NiPt}-0.2 \%$ & 853.2 & 856.6 & 862.1 & 870.1 & 874.4 & 880.2 & 70.9 & 74.2 & 68.1 & 74.9 \\
\hline $\mathrm{NiPt}-0.6 \%$ & 852.8 & 856.4 & 862.1 & 870.1 & 874.1 & 880.3 & 70.9 & 74.4 & 67.7 & 74.7 \\
\hline NiPt-1.0\% & 852.7 & 856.3 & 862.0 & 870.0 & 874.0 & 880.1 & 71.4 & 75.0 & 68.4 & 74.9 \\
\hline
\end{tabular}



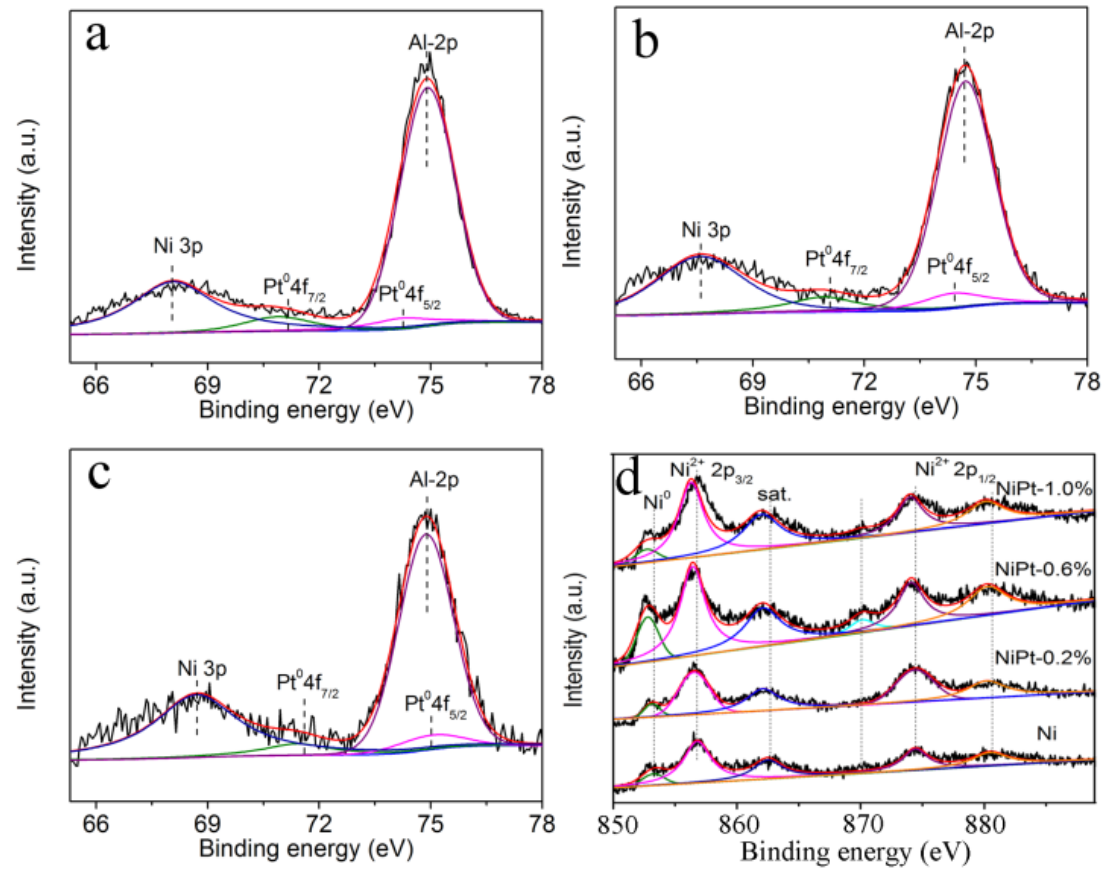

Figure 4. X-ray photoelectron spectroscopy (XPS) spectra of Pt and Ni core levels in the supported catalysts: (a) NiPt-0.2\%; (b) NiPt-0.6\%; (c) NiPt-1.0\% and (d) Ni.

\subsection{Evaluation of the Catalytic Activity}

The catalytic activities of the as-prepared $\mathrm{Ni}$ and $\mathrm{NiPt}(0.2 \%, 0.6 \%$, and $1.0 \%)$ catalysts were evaluated using a probe reaction, i.e., the reduction of 4-NP into 4-AP. The reduction was conducted in an aqueous solution of 4-NP with the addition of $\mathrm{NaBH}_{4}$ as a reducing agent. The Ultraviolet-visible (UV-VIS) absorption spectra were recorded with time to monitor the transformation from 4-NP to 4-AP due to their distinct absorption positions. The original adsorption of 4-NP peaked at $317 \mathrm{~nm}$ (Figure 5a). The absorption shifted to $400 \mathrm{~nm}$ when the freshly prepared aqueous solution of $\mathrm{NaBH}_{4}$ was added, and the color of the solution immediately changed from the pristine light yellow to bright yellow (the inset of Figure 5a). This redshift was ascribed to the rapid formation of 4-nitrophenolate ions in alkaline solution upon the addition of $\mathrm{NaBH}_{4}$ [37]. When the NiPt- $0.6 \%$ catalysts were added to the solution, the bright yellow solution faded and became colorless in tens of seconds. The absorption at $400 \mathrm{~nm}$ sharply decreased, and the absorption at $300 \mathrm{~nm}$ from 4-AP appeared [38]. The evolution of absorbance spectra with time clearly showed the conversion from 4-NP to 4-AP in the presence of $\mathrm{NiPt}-0.6 \%$ catalysts (Figure $5 \mathrm{~b}$ ). The reduction was completed within around 100 seconds according to the decreasing absorbance at $400 \mathrm{~nm}$ and the increasing absorbance at $300 \mathrm{~nm}$, corresponding to the deletion of 4-NP and the formation of 4-AP, respectively.

The $\mathrm{Ni}$ and NiPt catalysts were compared based on the concentration changes of 4-NP as a function of time (Figure 5c). The reaction would not happen in the absence of catalysts. It was observed that the decrease in the concentration of 4-NP over the catalysts followed the order: $\mathrm{NiPt}-0.6 \%>\mathrm{NiPt}-0.2 \%>\mathrm{NiPt}-1.0 \%>\mathrm{Ni}$. The concentration of 4 -NP decreased to $10 \%$ of the initial value within 120 seconds over $\mathrm{NiPt}-0.6 \%$ catalysts. It was noted that the optimal catalysts were $\mathrm{NiPt}-0.6 \%$ rather than NiPt-1.0\% with a higher Pt content. This suggested that the activity of Ni catalysts could be enhanced by incorporating an appropriate amount of Pt. The excessive amount of $\mathrm{Pt}$ had a negative effect on the catalytic activity in the reduction of 4-NP to 4-AP. These findings were in agreement with the catalytic behaviors of $\mathrm{AuCu}$ alloy reported in a recent literature [39]. In that work, the reaction pathway for reduction of nitroaromatics to anilines was adjusted by tailoring the compositions of bimetallic nanocatalysts. A similar volcano curve associated with the yield of aniline was observed with the change of $\mathrm{Cu}$ contents. The volcano curve behavior indicated that the 
chemical compositions of the bimetallic nanocatalysts were important parameters for affecting the catalytic activity.
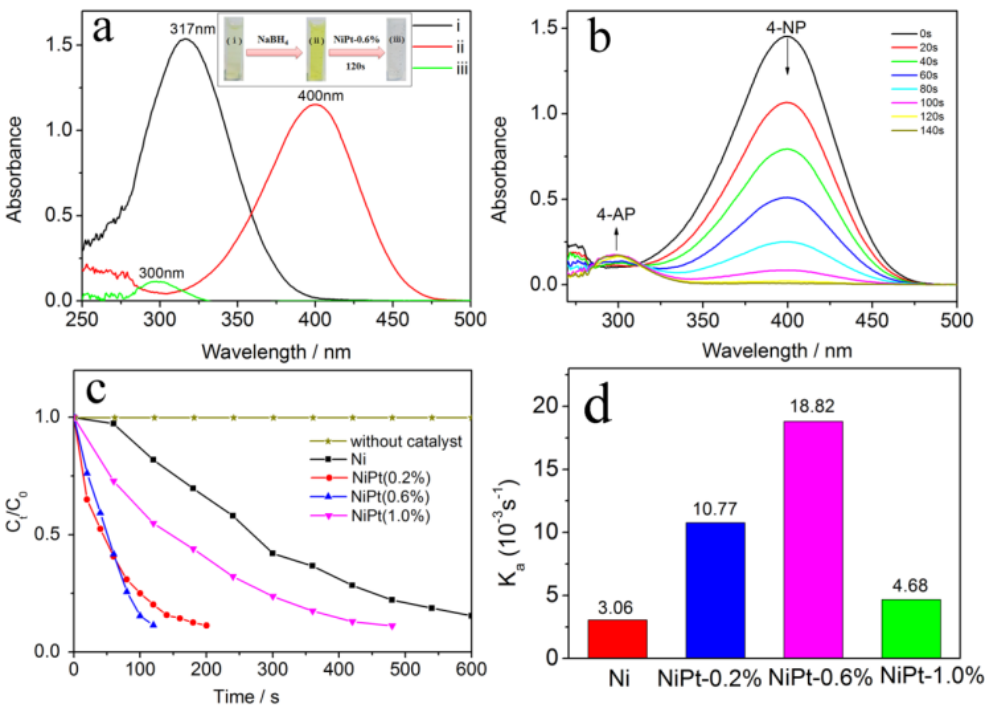

Figure 5. (a) Ultraviolet-visible (UV-VIS) absorption spectra of the solution before (i) and after (ii) the addition of $\mathrm{NaBH}_{4}$ and (iii) after the addition of NiPt- $0.6 \%$ catalyst; (b) time-dependent UV-VIS absorption spectra of the reduction of 4 -NP over the NiPt- $0.6 \%$ catalyst in aqueous solution at room temperature; (c) reduction of 4-NP over different catalysts as a function of time; (d) apparent rate constants $\left(K_{a}\right)$ of the reactions in the presence of supported catalysts.

The reduction rate of 4-NP was independent of the concentration of reducing agent $\left(\mathrm{NaBH}_{4}\right)$ since the initial concentration of $\mathrm{NaBH}_{4}$ greatly exceeded that of 4-NP ( 100 times). Thus, the reduction process could be described with pseudo-first-order kinetics with respect to the concentration of 4-NP [40]:

$$
-\ln \left(C_{t} / C_{0}\right)=K_{a} t
$$

where $C_{0}$ and $C_{t}$ (unit in $\mathrm{mM}$ ) were the concentrations of 4-NP at the beginning and at a certain time, respectively. Figure $5 \mathrm{~d}$ showed the apparent rate constants $\left(K_{\mathrm{a}}\right)$ for different catalysts, which were calculated according to equation 3 . The values of $K_{\mathrm{a}}$ for $\mathrm{NiPt}-0.2 \%, \mathrm{NiPt}-0.6 \%$, and NiPt- $1.0 \%$ catalysts were $0.01077,0.01882$, and $0.00468 \mathrm{~s}^{-1}$, respectively, all of which were higher than that of the Ni catalysts $\left(0.00306 \mathrm{~s}^{-1}\right)$. This could be caused by the strong interactions between $\mathrm{Ni}$ and Pt. The electronic structures of $\mathrm{Ni}$ were modified by incorporation of $\mathrm{Pt}$, which was consistent with the recent report on Ir-promoted Ni catalysts for hydrogenation reaction [18]. As to the different activities of NiPt catalysts, it might be due to the different exposed crystal planes of Ni NPs and Pt NPs. As shown in Figure 2c, the NiPt-0.6\% catalysts showed the Ni (200) plane besides the Ni (111) one. The crystal plane-dependent activity has been confirmed in metal-supported oxide catalysts [41]. Further studies on the correlations were required by constructing a less complicated model catalyst.

In addition, the $K_{\mathrm{a}}$ values of various catalysts were compared in Table 3. It was seen that the NiPt-0.6\% catalyst showed much larger $K_{a}$ value than the reported nickel catalysts $[4,6,14]$. Importantly, this catalyst exhibited higher activity than noble-metal and bimetallic ones such as DPNs (dendritic Pt nanoparticles) [11], reduced graphene oxide (RGO)/PtNi [35], Pt/ $\gamma-\mathrm{Al}_{2} \mathrm{O}_{3}[40$ ] and $\mathrm{Ni}-\mathrm{Pt}$ [42]. The comparisons further verified the superior catalytic activity of the optimal $\mathrm{NiPt}$ catalysts for 4-NP reduction and highlighted the very limited use of noble-metal $\mathrm{Pt}$ in the as-prepared high-performance catalysts. 
Table 3. Comparisons of the apparent rate constant $\left(K_{a}\right)$ for 4-NP reduction over various catalysts.

\begin{tabular}{|c|c|c|c|}
\hline Catalysts & Reaction Conditions $^{1}$ & $K_{a}^{2} / 10^{-3} \mathrm{~s}^{-1}$ & References \\
\hline NiPt-0.6\% (Ni: 36.98 wt \% Pt: 0.347 wt \%) & $15.5 \mathrm{mg}, 2 \mathrm{mM}, 25^{\circ} \mathrm{C}, 0.25 \mathrm{M}$ & 18.82 & This work \\
\hline $\mathrm{Pd}_{0.05} / \mathrm{G}$ & $4 \mathrm{mg}, 0.3 \mathrm{mM}, 25^{\circ} \mathrm{C}, 0.1 \mathrm{M}$ & 36.5 & [1] \\
\hline $\mathrm{Ir} / \mathrm{IrO} x$ & $-, 20 \mathrm{mM}, 25^{\circ} \mathrm{C}, 0.2 \mathrm{M}$ & 2.57 & [2] \\
\hline $230 \mathrm{~nm} \mathrm{Ni} / \mathrm{SiO}_{2} \mathrm{MHMs}(\mathrm{Ni}: 14.6 \mathrm{wt} \%$ ) & $3 \mathrm{mg}, 5 \mathrm{mM}, 25^{\circ} \mathrm{C}, 0.2 \mathrm{M}$ & 4.5 & [4] \\
\hline Ni NPs & $3 \mathrm{mg}, 0.1 \mathrm{mM}, 20^{\circ} \mathrm{C}, 0.2 \mathrm{M}$ & 2.7 & [6] \\
\hline $\mathrm{Pd}-\mathrm{Fe}_{3} \mathrm{O}_{4}(1.2 \mathrm{wt} \%)$ & $10 \mathrm{mg}, 21.56 \mathrm{mM}, 25^{\circ} \mathrm{C}, 0.1 \mathrm{MPa}$ & - & [7] \\
\hline DPNs & $-, 2 \mathrm{mM}, 25^{\circ} \mathrm{C}, 0.3 \mathrm{M}$ & 0.75 & [11] \\
\hline $\mathrm{Ni} / \mathrm{TiO}_{2}$ & $400 \mathrm{mg},-, 100{ }^{\circ} \mathrm{C}, 1.5 \mathrm{MPa}$ & - & [14] \\
\hline $\mathrm{Ni} / \mathrm{SiO}_{2} @ \mathrm{Au} \mathrm{MHMs}$ & $4 \mathrm{mg}, 5 \mathrm{mM}, 25^{\circ} \mathrm{C}, 0.2 \mathrm{M}$ & 10 & [15] \\
\hline RGO/PtNi (25:75) & $3 \mathrm{mg}, 5 \mathrm{mM}, 25^{\circ} \mathrm{C}, 1.5 \mathrm{M}$ & 1.12 & [35] \\
\hline TAC-Ag-1.0 & $0.004 \mathrm{mg}, 0.103 \mathrm{mM}, 25^{\circ} \mathrm{C}, 0.3 \mathrm{M}$ & 5.19 & [38] \\
\hline $\mathrm{Au}-\mathrm{Cu}$ alloy NP & $50 \mathrm{mg},-, 60{ }^{\circ} \mathrm{C},-$ & - & [39] \\
\hline $\mathrm{Pt} / \gamma-\mathrm{Al}_{2} \mathrm{O}_{3}(2.7 \mathrm{wt} \%)$ & $0.5 \mathrm{mg}, 1 \mathrm{mM}, 22^{\circ} \mathrm{C}, 0.1 \mathrm{M}$ & 0.53 & [40] \\
\hline Ni-Pt (96:4) & $0.004 \mathrm{mg}, 0.085 \mathrm{mM}, 25^{\circ} \mathrm{C}, 0.012 \mathrm{M}$ & 1.93 & [42] \\
\hline AuNPs/SNTs & $8 \mathrm{mg}, 0.12 \mathrm{mM}, 25^{\circ} \mathrm{C}, 0.005 \mathrm{M}$ & 10.64 & [43] \\
\hline $\mathrm{AuNP} / \mathrm{CeO}_{2}(\mathrm{Au}: 0.031 \mathrm{mg})$ & $10 \mathrm{mg}, 0.12 \mathrm{mM}, 25^{\circ} \mathrm{C}, 0.005 \mathrm{M}$ & 2.25 & [44] \\
\hline
\end{tabular}

${ }^{1}$ Reaction conditions follow the order of amount of catalyst, the initial concentration of 4-NP, temperature, $\mathrm{H}_{2}$ pressure/the concentration of $\mathrm{NaBH}_{4} ;{ }^{2} K_{a}$ : Apparent rate constant.

Generally, the formation of a bimetallic structure can change the electronic states of metals, particularly the d-band center of the involved metal atoms, which is highly relevant to their catalytic activity [45]. The variations of the d-band in metals have been theoretically studied using density functional theory (DFT) computations assuming some specific extended-surface models [46,47]. Recently, the theory has also been applied to bimetallic systems to correlate the changes in the electronic states with the catalytic activities in a variety of reactions [48]. With regard to the NiPt NPs studied in this work, Ni was reduced in situ and enriched on the surface from a hybrid of LDH/carbon precursor. The pristine Ni NPs showed the activity towards the reduction of 4-NP. Upon introducing $\mathrm{Pt}$ to the Ni catalysts, the local electronic structures of the Ni were affected, and the electron density on the $\mathrm{Ni}$ was changed, which was dependent on the bimetallic compositions [42]. It was found that the $\mathrm{NiPt}-0.6 \%$ catalysts had higher activity than the NiPt- $1.0 \%$ with a larger content of Pt. It could be due to the different exposed crystal planes of Ni NPs (Figure 2c).

On the other hand, small nanoparticles and excellent dispersions resulted in high activity in many cases $[49,50]$. The sizes of nickel crystallites as estimated by TEM decreased with increasing amount of Pt. No obvious agglomeration of Ni NPs was observed although the Ni loading was very high (36\%-39\%). This highlighted the advantages of the precursor method from LDH/carbon hybrid owing to the lattice anchoring effect of metal ions in the layers of LDH [22,25]. The Pt-modified Ni NPs were more active for adsorbing and cleaving $\mathrm{H}_{2}$ molecules than the pristine Ni NPs during reduction of 4-NP, owing to a higher electron density of NiPt active sites [51]. The produced active hydrogen atoms reacted with 4-NP on the active sites to generate 4-AP. A reaction pathway was shown in Figure 6. First, $\mathrm{NaBH}_{4}$ rapidly reacted with water to release $\mathrm{H}_{2}$, in which the sodium metaborate $\left(\mathrm{NaBO}_{2}\right)$ was formed as a byproduct. Then, the $\mathrm{H}_{2}$ split $\mathrm{H}-\mathrm{H}$ bond into $\mathrm{H}$ atoms, which adsorbed on the surface of metal nanoparticles. There was no doubt that the increase in chemisorbed $\mathrm{H}$ atoms on $\mathrm{NiPt}$ nanoparticles could improve the reducibility. It was accepted that the more hydrogen adsorbed, the higher the catalytic activity exhibited [18]. The negatively-charged hydrogen in the metal-hydrogen bond attacked the positively charged nitrogen within the nitro group of 4-NP. Subsequently the nitro group was reduced to the nitroso group intermediate, followed by the reaction of two hydrogen atoms to form hydroxylamine. Finally, the hydroxylamine was further reduced to amino group to obtain 4-AP. 
$\mathrm{NaBH}_{4}+2 \mathrm{H}_{2} \mathrm{O} \longrightarrow \mathrm{NaBO}_{2}+4 \mathrm{H}_{2}$
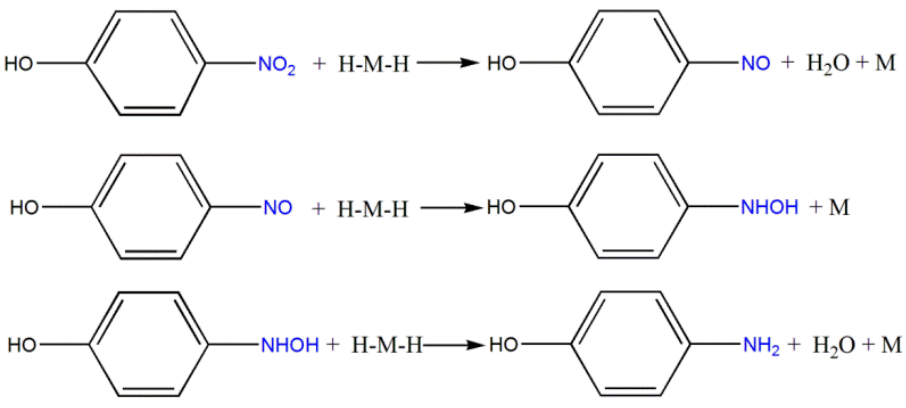

$\mathrm{M}$ : metal

Figure 6. Reaction pathways for the reduction of 4-NP to 4-AP: (a) $\mathrm{NaBH}_{4}$ hydrolyzed to release $\mathrm{H}_{2}$; (b) $\mathrm{H}_{2}$ molecules split to $\mathrm{H}$ atoms on the surface of metal NPs and reacted with 4-NP; (c) H atoms reacted with the nitrosophenol intermediate to form hydroxylamine; (d) hydroxylamine was further reduced to the final product 4-AP. H-M-H represents the split of $\mathrm{H}_{2}$ molecules on the surface of metal NPs.

The native magnetic property of the nanocatalysts caused by Ni made them economically and easily separated after reactions using an external magnet (Figure 7), and the catalysts were conveniently recycled and reused in a fresh solution.

a)

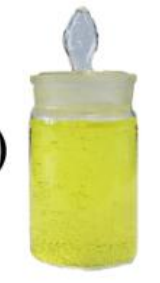

d)

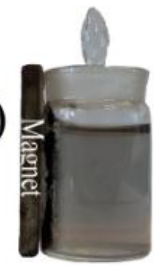

b)

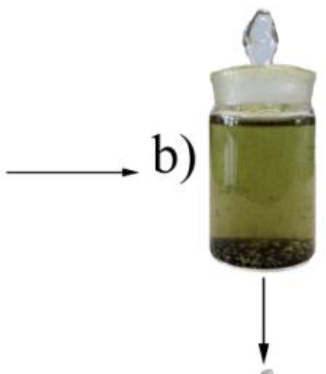

separation $\mathbf{C}$

c)

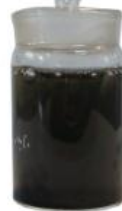

Figure 7. Separation of NiPt- $0.6 \%$ from solution by a magnet: (a) before addition of the catalyst; (b) after addition of the catalyst; (c) the suspension solution after reaction; (d) separation of solid catalysts with a magnet.

\section{Experimental Section}

\subsection{Materials}

Hexachloroplatinic acid $\left(\mathrm{H}_{2} \mathrm{PtCl}_{6} \cdot 6 \mathrm{H}_{2} \mathrm{O}, 99.9 \%\right)$ was purchased from Sinopharm Chemical Reagent Co., Ltd. (Shanghai, China). Glucose anhydrous and $\mathrm{NaBH}_{4}$ were purchased from Kermel Chemical Reagent Co., Ltd. (Tianjin, China). 4-nitrophenol, received from Macklin Biochemical Co., Ltd. (Shanghai, China), was used without further purification. Other chemicals and reagents were all analytical reagent grade and used as received without further purification. Deionized water was used throughout the process. 


\subsection{Synthesis of NiAl-LDH Precursor}

A mixture of $\mathrm{Ni}\left(\mathrm{NO}_{3}\right)_{2} \cdot 6 \mathrm{H}_{2} \mathrm{O}$ and $\mathrm{Al}\left(\mathrm{NO}_{3}\right)_{3} \cdot 9 \mathrm{H}_{2} \mathrm{O}$ were dissolved in $30 \mathrm{~mL}$ of deionized water to form a clear salt solution $\left(\left[\mathrm{Ni}^{2+}\right]=0.2 \mathrm{M},\left[\mathrm{Al}^{3+}\right]=0.1 \mathrm{M}\right)$. The salt solution was rapidly poured into a $30 \mathrm{~mL} \mathrm{NaOH}$ and $\mathrm{Na}_{2} \mathrm{CO}_{3}$ solution $\left(\left[\mathrm{OH}^{-}\right]=1.6\left[\mathrm{Ni}^{2+}+\mathrm{Al}^{3+}\right],\left[\mathrm{CO}_{3}{ }^{2-}\right]=2\left[\mathrm{Al}^{3+}\right]\right)$ within several tens of seconds under vigorous stirring. The mixture solution was further stirred for $10 \mathrm{~min}$ at room temperature. The resulting suspension was then centrifuged and re-dispersed in deionized water for five cycles to obtain LDH precipitate. The resulting precipitate was transferred and dispersed into a Teflon-lined autoclave ( $100 \mathrm{~mL}$ total volume), and $80 \mathrm{~mL}$ of deionized water was added to it. The autoclave was then tightly sealed and maintained at $150{ }^{\circ} \mathrm{C}$ for $10 \mathrm{~h}$. The resulting bluish green suspension was directly vacuum-freeze-dried overnight to collect the solid NiAl-LDH powder.

\subsection{Synthesis of LDH/Carbon Composites and Supported NiPt Catalysts}

A certain amount of $\mathrm{H}_{2} \mathrm{PtCl}_{6} \cdot 6 \mathrm{H}_{2} \mathrm{O}$ was added to $30 \mathrm{~mL}$ of glucose $\left(\mathrm{C}_{6} \mathrm{H}_{12} \mathrm{O}_{6}\right)$ solution $\left(\left[\mathrm{C}_{6} \mathrm{H}_{12} \mathrm{O}_{6}\right]=2.5\left[\mathrm{Ni}^{2+}+\mathrm{Al}^{3+}\right]\right)$. The precipitate obtained via the above-mentioned room-temperature co-precipitation was dispersed in the mixture solution. The resultant solution was transferred into an autoclave with the same fill volume and maintained at the same temperature $\left(150{ }^{\circ} \mathrm{C}\right)$ for the same period of time $(10 \mathrm{~h})$. Subsequently, the product was centrifuged and washed with deionized water and ethanol five times. Finally, the precipitate was freeze-dried overnight to obtain LDH/C composites and $\mathrm{Pt} / \mathrm{LDH}-\mathrm{C}$. The resulting composites were loaded into an alumina boat and calcined in a tube furnace in a flowing $\mathrm{N}_{2}$ atmosphere. The furnace was heated to a preset temperature at a rate of $5{ }^{\circ} \mathrm{C} / \mathrm{min}$, and the temperature was maintained for $2 \mathrm{~h}$. After the reaction, the furnace was naturally cooled to room temperature. The obtained black product was denoted as NiPt- $x$, where $x$ is the theoretical loading percentage of $\mathrm{Pt}(\mathrm{wt} \%)$.

\subsection{Characterizations}

UV-VIS absorption spectra were recorded using a (TU-1810 spectrometer, Purkinje, Inc., Beijing, China. TEM and high-resolution TEM (HRTEM) images were obtained using a JEM-2100 microscope (JEOL, Tokyo, Japan) with an Oxford INCA detector (Oxford-instruments, Shanghai, China) operating at $200 \mathrm{kV}$. The compositions of the as-prepared catalysts were determined through inductively coupled plasma-atomic emission spectroscopy (ICP-AES) (ICPS-7500 Spectrometer, Shimadzu, Inc., Beijing, China) Powder XRD analyses were performed using a Bruker D8 Advanced diffractometer (Bruker, Beijing, China) with $\mathrm{Cu} \mathrm{K} \alpha$ radiation, and the scanning angle $2 \theta$ ranged from $5^{\circ}$ to $80^{\circ}$. XPS measurements were performed using a VG ESCALAB250 (Thermo Fisher Scientific, MA, USA) with $\mathrm{Al} \mathrm{K}_{\alpha}$ radiation $(\mathrm{h} v=1486.6 \mathrm{eV})$. The specific surface areas were measured via $\mathrm{N}_{2}$-adsorption at $77 \mathrm{~K}$ using a static volumetric Quantachrome Autosorb-1C-VP Analyser (Quantachrome, Shanghai, China). The specific surface area was calculated using a Brunauer-Emmett-Teller (BET) method.

\subsection{Catalytic Evaluation}

Catalytic reduction reactions of 4-nitrophenols were conducted at room temperature $\left(25^{\circ} \mathrm{C}\right)$ in the presence of NiPt catalysts with varying Pt content. Typically, aqueous solutions of 4-NP $(2 \mathrm{mM})$ and $\mathrm{NaBH}_{4}(0.25 \mathrm{M})$ were freshly prepared. NiPt catalyst in the amount of $15.5 \mathrm{mg}$ was dispersed into $40 \mathrm{~mL}$ of 4-NP and $\mathrm{NaBH}_{4}$ mixture solutions under continuous stirring. To evaluate the reaction progress, approximately $1 \mathrm{~mL}$ of solution was taken out of the reaction mixture at specified time intervals and subsequently diluted 20 times with deionized water. This step was followed by recording of the UV-VIS spectra of the solution to examine the concentration of 4-NP by monitoring the adsorption peak at $400 \mathrm{~nm}$. 


\section{Conclusions}

The supported NiPt nanocatalysts were synthesized by an in situ reduction strategy from Pt@LDH/carbon composites precursor. The precursor method ensured the formation of nanosized $(\sim 10 \mathrm{~nm})$ and aggregate-free Ni NPs. The incorporation of Pt to the pristine Ni catalysts led to the enhanced activity towards the reduction of 4-NP to 4-AP because the modification of Pt affected the electronic structures of Ni. The optimal NiPt catalysts with an appropriate amount of Pt showed excellent activity in the reduction of 4 -NP. The apparent rate constant $\left(K_{\mathrm{a}}\right)$ reached $18.82 \times 10^{-3} \mathrm{~s}^{-1}$, which was 6.2 times higher than that of Ni catalysts and much higher than most of reported catalysts in the literaures. The present method for bimetallic catalysts could be extended to other compositions owing to the adjustable components in LDHs to improve the catalytic activity of the monometallic ones and simultaneously to minimize the utilization of noble metals.

Acknowledgments: This work was supported by the 973 Program (Grant 2014CB932104), the National Natural Science Foundation of China (NSFC), the Beijing Natural Science Foundation (Grant 2152022), the Fundamental Research Funds for the Central Universities (Grant YS1406) and Jiangsu Key Laboratory of Advanced Catalytic Materials and Technology (Grant BM2012110).

Author Contributions: Xu Xiang and Bing Zhang conceived the idea and designed the experiments. Huishan Shang, Kecheng Pan and Lu Zhang were involved in the synthesis, characterization and catalytic evaluation of catalysts. Xu Xiang, Huishan Shang and Bing Zhang conducted the discussion, interpreted the data and wrote the manuscript. All authors read the manuscript and agreed the submission.

Conflicts of Interest: The authors declare no conflict of interest.

\section{References}

1. Sun, J.; Fu, Y.; He, G.; Sun, X.; Wang, X. Catalytic hydrogenation of nitrophenols and nitrotoluenes over a palladium/graphene nanocomposite. Catal. Sci. Technol. 2014, 4, 1742-1748. [CrossRef]

2. Xu, D.; Diao, P.; Jin, T.; Wu, Q.; Liu, X.; Guo, X.; Gong, H.; Li, F.; Xiang, M.; Ronghai, Y. Iridium oxide nanoparticles and iridium/iridium oxide nanocomposites: Photochemical fabrication and application in catalytic reduction of 4-nitrophenol. ACS Appl. Mater. Interfaces 2015, 7, 16738-16749. [CrossRef] [PubMed]

3. Liu, W.-J.; Tian, K.; Jiang, H. One-pot synthesis of $\mathrm{Ni-NiFe} \mathrm{O}_{4} /$ carbon nanofiber composites from biomass for selective hydrogenation of aromatic nitro compounds. Green Chem. 2015, 17, 821-826. [CrossRef]

4. Niu, Z.; Zhang, S.; Sun, Y.; Gai, S.; He, F.; Dai, Y.; Li, L.; Yang, P. Controllable synthesis of $\mathrm{Ni} / \mathrm{SiO}_{2}$ hollow spheres and their excellent catalytic performance in 4-nitrophenol reduction. Dalton Trans. 2014, 43, 16911-16918. [CrossRef] [PubMed]

5. Mohan, V.; Pramod, C.; Suresh, M.; Reddy, K.H.P.; Raju, B.D.; Rao, K.R. Advantage of Ni/SBA-15 catalyst over $\mathrm{Ni} / \mathrm{MgO}$ catalyst in terms of catalyst stability due to release of water during nitrobenzene hydrogenation to aniline. Catal. Commun. 2012, 18, 89-92. [CrossRef]

6. Jiang, Z.; Xie, J.; Jiang, D.; Wei, X.; Chen, M. Modifiers-assisted formation of nickel nanoparticles and their catalytic application to $p$-nitrophenol reduction. CrystEngComm 2013, 15, 560-569. [CrossRef]

7. Zhang, D.; Chen, L.; Ge, G. A green approach for efficient $p$-nitrophenol hydrogenation catalyzed by a Pd-based nanocatalyst. Catal. Commun. 2015, 66, 95-99. [CrossRef]

8. Kumar, A.; Kumar, P.; Joshi, C.; Manchanda, M.; Boukherroub, R.; Jain, S.L. Nickel decorated on phosphorous-doped carbon nitride as an efficient photocatalyst for reduction of nitrobenzenes. Nanomaterials 2016, 6. [CrossRef]

9. Deka, P.; Deka, R.C.; Bharali, P. In situ generated copper nanoparticle catalyzed reduction of 4-nitrophenol. New J. Chem. 2014, 38, 1789-1793. [CrossRef]

10. Gao, Y.; Ding, X.; Zheng, Z.; Cheng, X.; Peng, Y. Template-free method to prepare polymer nanocapsules embedded with noble metal nanoparticles. Chem. Commun. 2007, 36, 3720-3722. [CrossRef] [PubMed]

11. Wang, J.; Zhang, X.-B.; Wang, Z.-L.; Wang, L.-M.; Xing, W.; Liu, X. One-step and rapid synthesis of "clean" and monodisperse dendritic Pt nanoparticles and their high performance toward methanol oxidation and p-nitrophenol reduction. Nanoscale 2012, 4, 1549-1552. [CrossRef] [PubMed] 
12. Baruah, B.; Gabriel, G.J.; Akbashev, M.J.; Booher, M.E. Facile synthesis of silver nanoparticles stabilized by cationic polynorbornenes and their catalytic activity in 4-nitrophenol reduction. Langmuir 2013, 29, 4225-4234. [CrossRef] [PubMed]

13. Gangula, A.; Podila, R.; Karanam, L.; Janardhana, C.; Rao, A.M. Catalytic reduction of 4-nitrophenol using biogenic gold and silver nanoparticles derived from Breynia rhamnoides. Langmuir 2011, 27, 15268-15274. [CrossRef] [PubMed]

14. Wu, Z.; Chen, J.; Di, Q.; Zhang, M. Size-controlled synthesis of a supported Ni nanoparticle catalyst for selective hydrogenation of $p$-nitrophenol to $p$-aminophenol. Catal. Commun. 2012, 18, 55-59. [CrossRef]

15. Zhang, S.; Gai, S.; He, F.; Dai, Y.; Gao, P.; Li, L.; Chen, Y.; Yang, P. Uniform Ni/SiO $2 @ A u$ magnetic hollow microspheres: Rational design and excellent catalytic performance in 4-nitrophenol reduction. Nanoscale 2014, 6, 7025-7032. [CrossRef] [PubMed]

16. Watanabe, M.; Yamashita, H.; Chen, X.; Yamanaka, J.; Kotobuki, M.; Suzuki, H.; Uchida, H. Nano-sized Ni particles on hollow alumina ball: Catalysts for hydrogen production. Appl. Catal. B Environ. 2007, 71, 237-245. [CrossRef]

17. Wang, D.; Astruc, D. The golden age of transfer hydrogenation. Chem. Rev. 2015, 115, 6621-6686. [CrossRef] [PubMed]

18. Lin, W.; Cheng, H.; He, L.; Yu, Y.; Zhao, F. High performance of Ir-promoted $\mathrm{Ni} / \mathrm{TiO}_{2}$ catalyst toward the selective hydrogenation of cinnamaldehyde. J. Catal. 2013, 303, 110-116. [CrossRef]

19. Wang, S.; Lin, W.; Zhu, Y.; Xie, Y.; McCormick, J.R.; Huang, W.; Chen, J.G. Pd-based bimetallic catalysts prepared by replacement reactions. Catal. Lett. 2007, 114, 169-173. [CrossRef]

20. Zhao, Z.-F.; Wu, Z.-J.; Zhou, L.-X.; Zhang, M.-H.; Li, W.; Tao, K.-Y. Synthesis of a nano-nickel catalyst modified by ruthenium for hydrogenation and hydrodechlorination. Catal. Commun. 2008, 9, 2191-2194. [CrossRef]

21. Nishikawa, J.; Miyazawa, T.; Nakamura, K.; Asadullah, M.; Kunimori, K.; Tomishige, K. Promoting effect of $\mathrm{Pt}$ addition to $\mathrm{Ni} / \mathrm{CeO}_{2} / \mathrm{Al}_{2} \mathrm{O}_{3}$ catalyst for steam gasification of biomass. Catal. Commun. 2008, 9, 195-201. [CrossRef]

22. Xiang, X.; Bai, L.; Li, F. Formation and catalytic performance of supported Ni nanoparticles via self-reduction of hybrid NiAl-LDH/C composites. AIChE J. 2010, 56, 2934-2945. [CrossRef]

23. Wang, Y.; He, W.; Wang, L.; Yang, J.; Xiang, X.; Zhang, B.; Li, F. Highly active supported Pt nanocatalysts synthesized by alcohol reduction towards hydrogenation of cinnamaldehyde: Synergy of metal valence and hydroxyl groups. Chem. Asian J. 2015, 10, 1561-1570. [CrossRef] [PubMed]

24. Xiang, X.; He, W.; Xie, L.; Li, F. A mild solution chemistry method to synthesize hydrotalcite-supported platinum nanocrystals for selective hydrogenation of cinnamaldehyde in neat water. Catal. Sci. Technol. 2013, 3, 2819-2827. [CrossRef]

25. Xiang, X.; Hima, H.I.; Wang, H.; Li, F. Facile Synthesis and Catalytic Properties of nickel-based mixed-metal oxides with mesopore networks from a novel hybrid composite precursor. Chem. Mater. 2007, 20, 1173-1182. [CrossRef]

26. Xiang, X.; Li, F.; Huang, Z. Recent advances in layered double hydroxide-based materials as versatile photocatalysts. Rev. Adv. Sci. Eng. 2014, 3, 158-171. [CrossRef]

27. Gawande, M.B.; Rathi, A.K.; Branco, P.S.; Nogueira, I.D.; Velhinho, A.; Shrikhande, J.J.; Indulkar, U.U.; Jayaram, R.V.; Ghumman, C.A.A.; Bundaleski, N. Regio-and chemoselective reduction of nitroarenes and carbonyl compounds over recyclable magnetic ferrite-nickel nanoparticles $\left(\mathrm{Fe}_{3} \mathrm{O}_{4}-\mathrm{Ni}\right)$ by using glycerol as a hydrogen source. Chem. Eur. J. 2012, 18, 12628-12632. [CrossRef] [PubMed]

28. Wang, Q.; Wang, Y.; Zhao, Y.; Zhang, B.; Yunyin, N.; Xiang, X.; Chen, R. Fabricating roughened surfaces on halloysite nanotubes via alkali etching for deposition of high-efficiency Pt nanocatalysts. CrystEngComm 2015, 17, 3110-3116. [CrossRef]

29. Gawande, M.B.; Branco, P.S.; Varma, R.S. Nano-magnetite $\left(\mathrm{Fe}_{3} \mathrm{O}_{4}\right)$ as a support for recyclable catalysts in the development of sustainable methodologies. Chem. Soc. Rev. 2013, 42, 3371-3393. [CrossRef] [PubMed]

30. Stassi, J.P.; Zgolicz, P.D.; de Miguel, S.R.; Scelza, O.A. Formation of different promoted metallic phases in $\mathrm{PtFe}$ and PtSn catalysts supported on carbonaceous materials used for selective hydrogenation. J. Catal. 2013, 306, 11-29. [CrossRef] 
31. Bera, P.; Priolkar, K.; Gayen, A.; Sarode, P.; Hegde, M.; Emura, S.; Kumashiro, R.; Jayaram, V.; Subbanna, G. Ionic dispersion of Pt over $\mathrm{CeO}_{2}$ by the combustion method: Structural investigation by XRD, TEM, XPS, and EXAFS. Chem. Mater. 2003, 15, 2049-2060. [CrossRef]

32. Zhou, X.-W.; Zhang, R.-H.; Zhou, Z.-Y.; Sun, S.-G. Preparation of PtNi hollow nanospheres for the electrocatalytic oxidation of methanol. J. Power Sources 2011, 196, 5844-5848. [CrossRef]

33. Pawelec, B.; Damyanova, S.; Arishtirova, K.; Fierro, J.; Petrov, L. Structural and surface features of PtNi catalysts for reforming of methane with $\mathrm{CO}_{2}$. Appl. Catal. A 2007, 323, 188-201. [CrossRef]

34. Haber, J.A.; Cai, Y.; Jung, S.; Xiang, C.; Mitrovic, S.; Jin, J.; Bell, A.T.; Gregoire, J.M. Discovering Ce-rich oxygen evolution catalysts, from high throughput screening to water electrolysis. Energy Environ. Sci. 2014, 7, 682-688. [CrossRef]

35. Sahoo, P.K.; Panigrahy, B.; Bahadur, D. Facile synthesis of reduced graphene oxide/Pt-Ni nanocatalysts: Their magnetic and catalytic properties. RSC Adv. 2014, 4, 48563-48571. [CrossRef]

36. Karelovic, A.; Ruiz, P. Improving the hydrogenation function of $\mathrm{Pd} / \gamma-\mathrm{Al}_{2} \mathrm{O}_{3}$ catalyst by $\mathrm{Rh} / \gamma-\mathrm{Al}_{2} \mathrm{O}_{3}$ addition in $\mathrm{CO}_{2}$ methanation at low temperature. ACS Catal. 2013, 3, 2799-2812. [CrossRef]

37. Dhar, J.; Patil, S. Self-assembly and catalytic activity of metal nanoparticles immobilized in polymer membrane prepared via layer-by-layer approach. ACS Appl. Mater. Interfaces 2012, 4, 1803-1812. [CrossRef] [PubMed]

38. Rashid, M.H.; Mandal, T.K. Synthesis and catalytic application of nanostructured silver dendrites. J. Phys. Chem. C 2007, 111, 16750-16760. [CrossRef]

39. Xiao, Q.; Sarina, S.; Waclawik, E.R.; Jia, J.; Chang, J.; Riches, J.D.; Wu, H.; Zheng, Z.; Zhu, H. Alloying gold with copper makes for a highly selective visible-light photocatalyst for the reduction of nitroaromatics to anilines. ACS Catal. 2016, 6, 1744-1753. [CrossRef]

40. Dandapat, A.; Jana, D.; De, G. Synthesis of thick mesoporous $\gamma$-alumina films, loading of Pt nanoparticles, and use of the composite film as a reusable catalyst. ACS Appl. Mater. Interfaces 2009, 1, 833-840. [CrossRef] [PubMed]

41. Na, T.; Liu, J.; Wenjie, S. Tuning the shape of ceria nanomaterials for catalytic applications. Chin. J. Catal. 2013, 34, 838-850.

42. Ghosh, S.K.; Mandal, M.; Kundu, S.; Nath, S.; Pal, T. Bimetallic Pt-Ni nanoparticles can catalyze reduction of aromatic nitro compounds by sodium borohydride in aqueous solution. Appl. Catal. A 2004, 268, 61-66. [CrossRef]

43. Zhang, Z.; Shao, C.; Zou, P.; Zhang, P.; Zhang, M.; Mu, J.; Guo, Z.; Li, X.; Wang, C.; Liu, Y. In situ assembly of well-dispersed gold nanoparticles on electrospun silica nanotubes for catalytic reduction of 4-nitrophenol. Chem. Commun. 2011, 47, 3906-3908. [CrossRef] [PubMed]

44. Zhang, J.; Chen, G.; Chaker, M.; Rosei, F.; Ma, D. Gold nanoparticle decorated ceria nanotubes with significantly high catalytic activity for the reduction of nitrophenol and mechanism study. Appl. Catal. B 2013, 132, 107-115. [CrossRef]

45. Stamenkovic, V.R.; Mun, B.S.; Arenz, M.; Mayrhofer, K.J.; Lucas, C.A.; Wang, G.; Ross, P.N.; Markovic, N.M. Trends in electrocatalysis on extended and nanoscale Pt-bimetallic alloy surfaces. Nat. Mater. 2007, 6, 241-247. [CrossRef] [PubMed]

46. Nørskov, J.K.; Bligaard, T.; Logadottir, A.; Bahn, S.; Hansen, L.B.; Bollinger, M.; Bengaard, H.; Hammer, B.; Sljivancanin, Z.; Mavrikakis, M. Universality in heterogeneous catalysis. J. Catal. 2002, 209, 275-278. [CrossRef]

47. Greeley, J.; Nørskov, J.K.; Mavrikakis, M. Electronic structure and catalysis on metal surfaces. Annu. Rev. Phys. Chem. 2002, 53, 319-348. [CrossRef] [PubMed]

48. Zhou, W.P.; Lewera, A.; Larsen, R.; Masel, R.I.; Bagus, P.S.; Wieckowski, A. Size effects in electronic and catalytic properties of unsupported palladium nanoparticles in electrooxidation of formic acid. J. Phys. Chem. B 2006, 110, 13393-13398. [CrossRef] [PubMed]

49. Nie, Y.; Chen, S.; Ding, W.; Xie, X.; Zhang, Y.; Wei, Z. Pt/C trapped in activated graphitic carbon layers as a highly durable electrocatalyst for the oxygen reduction reaction. Chem. Commun. 2014, 50, 15431-15434. [CrossRef] [PubMed] 
50. Yang, X.; Chen, D.; Liao, S.; Song, H.; Li, Y.; Fu, Z.; Su, Y. High-performance Pd-Au bimetallic catalyst with mesoporous silica nanoparticles as support and its catalysis of cinnamaldehyde hydrogenation. J. Catal. 2012, 291, 36-43. [CrossRef]

51. Joseph, T.; Kumar, K.V.; Ramaswamy, A.; Halligudi, S. Au-Pt nanoparticles in amine functionalized MCM-41: Catalytic evaluation in hydrogenation reactions. Catal. Commun. 2007, 8, 629-634. [CrossRef]

(c) 2016 by the authors; licensee MDPI, Basel, Switzerland. This article is an open access article distributed under the terms and conditions of the Creative Commons Attribution (CC-BY) license (http://creativecommons.org/licenses/by/4.0/). 